\title{
МОЛЕКУЛЯРНАЯ БИОЛОГИЯ
}

УДК 575.174

\section{МОЛЕКУЛЯРНО-ГЕНЕТИЧЕСКИЕ ОСОБЕННОСТИ НЕТРАНСКРИБИРУЕМОГО CПЕЙCЕРА 5S-рДНК У HIPРОРНAE RHAMNOIDES L.}

\author{
О.С. Александров ${ }^{*}$ А.В. Евтухов, И.И. Киселёв, Г.И. Карлов \\ Центр молекулярной биотехнологии, Российский государственный аграрный университет - Московская \\ сельскохозяйственная академия имени К.А. Тимирязева; Россия, 127550, г. Москва, ул. Тимирязевская, д. 49 \\ *e-mail: olegsandrov@gmail.com
}

\begin{abstract}
Амплификация нетранскрибируемого спейсера 5S-рДНК облепихи крушиновидной (Hippophae rhamnoides L.) с помощью праймеров, подобранных на фланги соседних кодирующих областей, показала наличие единичного фрагмента. Данный фрагмент был клонирован и секвенирован. Было обнаружено, что длина нетраскрибируемого спейсера облепихи составляет 807 п.о. Анализ последовательности показал высокий уровень гомологии с ранее описанными микросателлитными локусами облепихи, лоха серебристого (Elaeagnus angustifolia L.) и джузгуна (Calligonum mongolicum Turcz.), включающими мотив (GA) $)_{9}$ Полученные результаты могут быть полезны для дальнейшего изучения организации генов рибосомной РНК.
\end{abstract}

Ключевые слова: 5S-рДНК, нетраскрибируемый спейсер, микросателлитный локус, Hippophae rhamnoides L., Elaeagnus angustifolia L., Calligonum mongolicum Turcz.

У большинства животных и семенных растений гены, кодирующие рибосомную РНK 5S-субъединицы, организованы в виде кластеров, состоящих из мономеров, располагающихся тандемно по принципу “голова-хвост" [1-3]. Каждый мономер включает в себя консервативную 120 -нуклеотидную кодируюшую область и нетраскрибируемый спейсер (NTS), длина и нуклеотидный состав которого, как правило, различаются у разных видов [4-6]. Полиморфизм NTS 5S-рДНК используют для филогенетических исследований, анализа гибридов и разработки видоспецифичных маркеров [7, 8]. Благодаря тому, что кодирующие участки кластеров 5S-рДНК консервативны, можно провести амплификацию NTS у широкого круга видов с помощью одной и той же пары праймеров, подобранной на фланги генов (рисунок). Часто используют системы праймеров, разработанные Пендасом и др. (1995); Брауном и Карлсоном (1997); Шмидтом (1994) [4, $9,10]$.

Облепиха крушиновидная (Hippophae rhamnoides L., $2 \mathrm{n}=24)$ - двудомный многоствольный кустарник (реже дерево) семейства Elaeagnaceae, имеющий обширный ареал преимущественно в северном полушарии Евразии и использующийся в качестве плодовой и лекарственной культуры [11]. Для биологической науки это растение интересно тем, что в его кариотипе имеются половые хромосомы. Было показано, что обычно в паре половых хромосом Y-хромосома короче X-хромосомы. Однако среди генотипов H. rhamnoides, произрастающих на территории Румынии, встречаются такие, у которых Y-хромосома значительно длиннее X-хромосомы [12]. Молекулярно-генетическому и цитогенетическому изучению облепихи крушиновидной посвящено не так много работ. Известно, что размер ее генома составляет $\sim 2,55 \times 10^{9}$ п.о./2C [13]. Для идентификации пола растений облепихи были предложены только маркёры на основе случайно амплифицируемой полиморфной ДНК (RAPD-маркёры). Также предпринимались попытки использования RAPD и других видов молекулярных маркёров для изучения полиморфизма облепихи [11].

Локусы 5S-рДНК у облепихи ещё не изучены. Данная работа является первым сообщением о последовательности NTS 5S-рДНК облепихи.

\section{Материалы и методы}

В работе использовались образцы облепихи крушиновидной сорта Ломоносовская, любезно предоставленные сектором дендрологии Ботанического сада МГУ. ДНК выделяли из молодых листьев облепихи согласно методике Дойл и Дойл 1990 [14]. Амплификацию NTS 5S-рДНК проводили на амплификаторе C1000 Touch ${ }^{\mathrm{TM}}$ Thermal Cycler (Bio-Rad, США), используя систему праймеров $5 \mathrm{~S} 1 / 5 \mathrm{~S} 2$ [8] и программу: 1) $94^{\circ} \mathrm{C}-5$ мин; 2) 30 циклов $\left(94^{\circ} \mathrm{C}-\right.$ $20 \mathrm{c}, 60^{\circ} \mathrm{C}-20 \mathrm{c}, 72^{\circ} \mathrm{C}-20 \mathrm{c}$.); 3) $72^{\circ} \mathrm{C}-10 \mathrm{мин.}$ Электрофоретическое разделение продуктов амплификации осуществляли в 1,5\%-ном агарозном геле при 5 В/см и фотографировали с помощью системы гель-документации Gel Doc XR+ (Bio-Rad, США). Продукт полимеразной цепной реакции (ПЦР) очищали с помощью набора GenJet ${ }^{\mathrm{TM}}$ PCR Purification Kit (Fermentas, Латвия) и клонировали в векторе pGEM-T Vector Easy (Promega, США) согласно инструкциям производителей. Отбор клонов со вставками осуществляли с помощью белоголубой селекции, размер вставок определяли с помощью ПЦР со стандартными праймерами М13. Из отобранных клонов выделяли плазмидную ДНК 

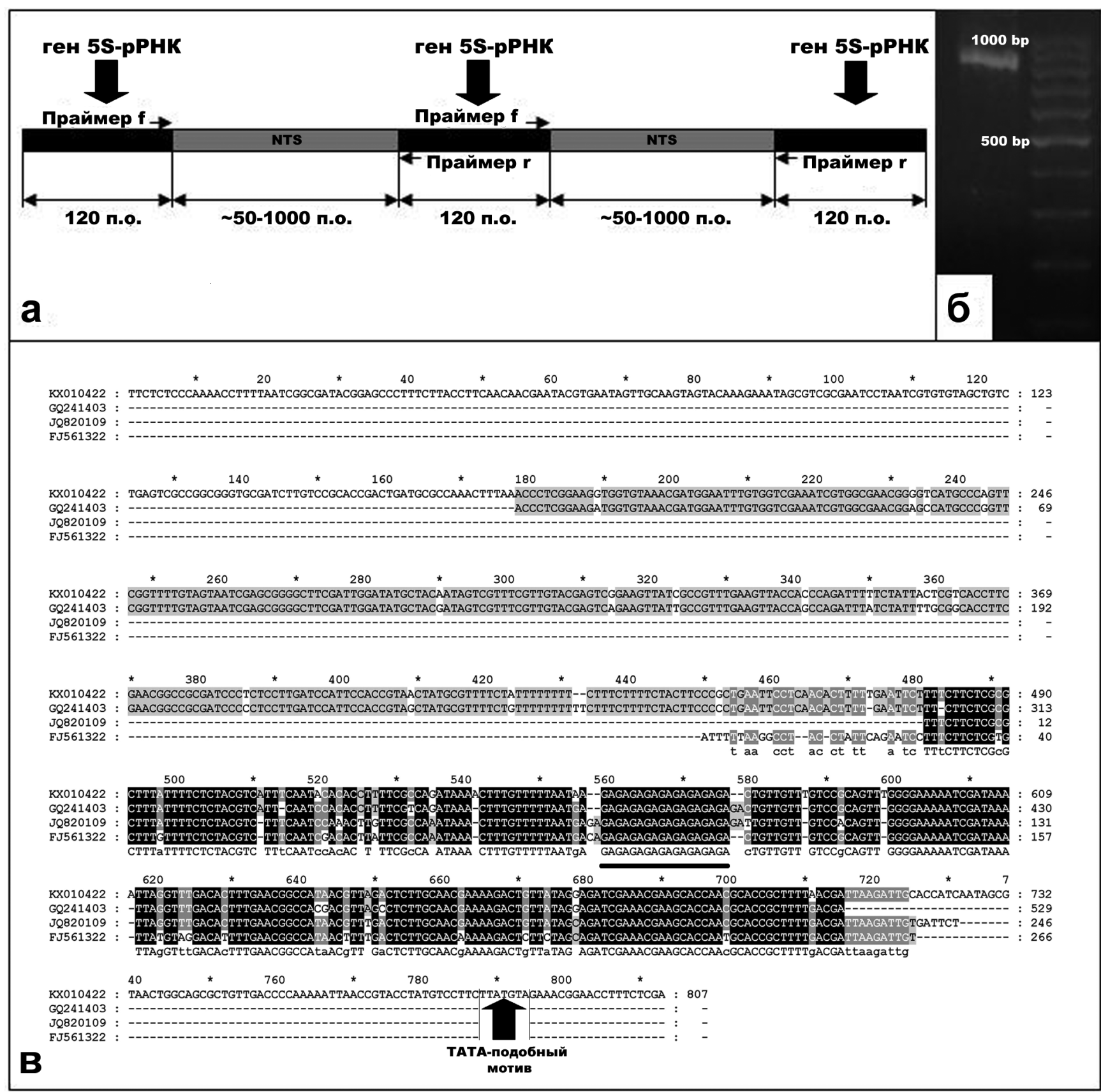

Рисунок. Организация локусов 5S-рДНК и система праймеров для амплификации NTS (a); электрофоретическая детекция продуктов ПЦР с праймерами 5S1/5S2 на матрице тотальной ДНК H. rhamnoides L., маркер молекулярного веса (100 bp DNA Ladder Jena Bioscience GmbH, Германия) (б); выравнивание последовательности NTS 5S-pДНК H. rhamnoides L. (KX010422) и гомологичных микросателлитных локусов H. rhamnoides L. (GQ241403), Elaeagnus angustifolia (JQ820109) и Calligonum mongolicum Turcz.

(FG561322), жирной линией выделен мотив (GA) ${ }_{9}$ (в)

с помощью GeneJET ${ }^{\mathrm{TM}}$ Plasmid Miniprep Kit (Fermentas, Латвия) и секвенировали на секвенаторе ABI 3139xl Genetic Analyzer (Applied Biosystems, USA). Секвенирование проводили по 3 раза с каждого из М13-праймеров. Анализ последовательностей проводили с помощью программного обеспечения GenDoc [15] и BLAST (http://blast.ncbi.nlm.nih. gov/Blast.cgi).

\section{Результаты и обсуждение}

Амплификация с праймерами 5S1/5S2 на матрице тотальной геномной ДНК Hippophae rhamnoides L. показала наличие единичного фрагмента длиной около 900 п.о. (рисунок). После клонирования ПЦР-продукта вставки 10 отобранных клонов были секвенированы. Идентичность полученных последовательностей составляла 97-98\%, что характерно для эволюционно зрелых видов, у которых давно произошла гомогенизация нетранскрибируемых спейсеров 5S-рДНК. Консенсусная 807-нуклеотидная последовательность NTS 5S-рДНК Hippophae rhamnoides L. была размещена в базе данных Genbank (KX010422).

Анализ полученной последовательности NTS 5S-pДНК Hippophae rhamnoides L. показал наличие восьминуклеотидного ТАТА-подобного мотива, 
расположенного на расстоянии 26 п.о. до начала гена 5S-pРНК (рисунок). Наличие таких мотивов, схожих с классической последовательностью ТАТАбокса, распространённого промотора архей и эукариот, является структурно-функциональной особенностью многих ранее описанных NTS 5S-рДНК.

Ещё одной особенностью NTS 5S-рДНК Hippophae rhamnoides L. является присутствие микросателлитного локуса (GA) 9 в позиции $-252 /-235$ от начала гена 5S-pPHK. Среди растений подобное явление (но с другими микросателлитными мотивами) описано лишь у Populus deltoides (мотив $(\mathrm{GAA})_{10-13}$ ) и ещё у нескольких видов тополей, а также у Lens culinaris (мотив (ТА) ${ }_{6-21}$ ) $[9,16,17]$. Поэтому можно заключить, что NTS 5S-рДНК с микросателлитным мотивом (GA) 9 у растений найден впервые. Наличие микросателлитного мотива в последовательности NTS 5S-рДНК, однако, часто встречается у рыб: $(\mathrm{GCT})_{10}$ у Potamotrygon motoro [18], (CA) ${ }_{13}$ y Merluccius albus [19], (GCT) $)_{8-11}$ y Micropterus salmoides [20], (CA) ${ }_{48}$ y Molva molva [21], $(\mathrm{CA})_{14}$ y Aulopus japonicus [22], (TTTG) $)_{5}$ y Danio rerio [23] и др. Широко известно, что NTS 5S-рДНК, как и многие другие спейсерные последовательности генома, являются эволюционно пластичными регионами. Эта пластичность обусловлена тем, что мутационные изменения в этих регионах не оказывают существенного влияния на функцию синтеза 5S-pРНК и, закрепляясь, достаточно быстро накапливаются. Появление микросателлитных повторов в NTS 5S-рДНК у облепихи, так же, как и у рассмотренных выше рыб и растений - это один из частных случаев данного процесса.

ВLAST-анализ NTS 5S-рДНК Hippophae rhamnoides L. выявил высокий уровень гомологии достаточно протяженных участков изучаемой последовательности с ранее секвенированными микро-

\section{СПИСОК ЛИТЕРАТУРЫ}

1. Martins C. Wasko A.P. Organization and evolution of 5S ribosomal DNA in the fish genome // Focus on Genome Research / Eds. C.R. Williams. Hauppauge: Nova Science Publishers, 2004. P. 289-319.

2. Wicke S., Costa A., Muñoz J., Quandt D. Restless 5S: the re-arrangement(s) and evolution of the nuclear ribosomal DNA in land plants // Mol. Phylogenet. Evol. 2011. Vol. 61. N 2. P. 321-332.

3. Vierna J., Wehner S., Höner zu Siederdissen C., Martínez-Lage A., Marz M. Systematic analysis and evolution of 5S ribosomal DNA in metazoans // Heredity. 2013. Vol. 111. N 5. P. $410-421$.

4. Pendas A.M., Moran P., Martinez J.L., Garcia-Vasquez E. Applications of 5S rDNA in Atlantic salmon, brown trout, and in Atlantic salmon $\times$ brown trout hybrid identification // Mol. Ecol. 1995. Vol. 4. N 2. P. 275-276.

5. Liu Z.L., Zhang D., Wang X.Q., Ma X.F. Intragenomic and interspecific $5 \mathrm{~S}$ rDNA sequence variation in five asian pines // Am. J. Bot. 2003. Vol. 90. N 1. P. 17-24.

6. Mythili Avadhani M.N., Immanuel Selvaraj C., Tharachand C., Rajasekharan P.E. Molecular characterization of medicinal and aromatic plants by 5S rRNA NTS and PCR сателлитными локусами Hippophae rhamnoides L. (Elaeagnaceae) [11], Elaeagnus angustifolia (Elaeagnaceae) [24] и Calligonum mongolicum Turcz. (Polygonaсеае) [25] (рисунок; таблица). Во всех этих последовательностях также присутствует тандемный мотив $(\mathrm{GA})_{9}$.

\section{Таблица}

Идентичность участков NTS 5SpДНК H. rhamnoides L. и гомологичных микросателлитных локусов

\begin{tabular}{|c|l|c|c|}
\hline $\begin{array}{c}\text { Название } \\
\text { локуса }\end{array}$ & \multicolumn{1}{|c|}{ Вид } & $\begin{array}{c}\text { Длина участка, } \\
\text { гомологичног NTS } \\
\text { 5S-рДНK } \text { H. } \\
\text { rhamnoides L., п.о. }\end{array}$ & $\begin{array}{c}\text { Идентич- } \\
\text { ность, \% }\end{array}$ \\
\hline GQ241403 & $\begin{array}{l}\text { Hippophae } \\
\text { rhamnoides L. }\end{array}$ & 529 & 93 \\
\hline JQ820109 & $\begin{array}{l}\text { Elaeagnus } \\
\text { angustifolia }\end{array}$ & 238 & 92 \\
\hline FJ561322 & $\begin{array}{l}\text { Calligonum } \\
\text { mongolicum } \\
\text { Turcz. }\end{array}$ & 239 & 89 \\
\hline
\end{tabular}

Данная работа является первым шагом в изучении локусов 5S-pДНК у облепихи и её сородичей и может быть востребована при установлении молекулярно-филогенетических отношений между видами Elaeagnaceae, а также внести вклад в понимание организации генов 5S-pPHК у растений.

Работа выполнена при финансовой поддержке ведущих научных школ Российской Федерации (Грант Президента № НШ-8315.2016.11) и с использованием уникальной научной установки "Комплекс для проведения междисциплинарных исследований в области сравнительной и функциональной геномики растений”.

RFLP - A mini review // Res. Biotechnol. 2012. Vol. 3. N 2. P. 41-48.

7. Brown G.R., Carlson J.E. Molecular cytogenetics of the genes encoding $18 \mathrm{~s}-5.8 \mathrm{~s}-26 \mathrm{~s}$ rRNA and $5 \mathrm{~s}$ rRNA in two species of spruce (Picea) // Theor. Appl. Genet. 1997. Vol. 95. N 1-2. P. 1-9.

8. Schmidt T., Schwarzacher T., Heslop-Harrison J.S. Physical mapping of rRNA genes by fluorescent in situ hybridization and structural analysis of 5S rRNA genes and intergenic spacer sequences in sugar beet (Beta vulgaris) // Theor. Appl. Genet. 1994. Vol. 88. N 6. P. 629-636.

9. Wilson N. Genome analysis of Populus species: assessment of genetic diversity of $P$. deltoides, characterization of wide hybrids and phylogenetic analysis using molecular markers. New Delhi: Teri University, 2013. 177 p.

10. Александров О.С., Карлов Г.И., Сорокин А.Н., Потапенко H.X. Создание системы молекулярных маркеров для видовой идентификации представителей рода Тополь и анализа гибридов // Материалы III Всероссийской молодёжной конференции с участием иностранных учёных “Перспективы развития и проблемы современной ботаники” (Новосибирск, 10-14 ноября 2014 г.). Новосибирск: Академиздат, 2014. С. 123-124. 
11. Islam A., Sinha P., Sharma S.S., Negi M.S., Tripathi S.B. Isolation and characterization of novel polymorphic microsatellite loci in Hippophae rhamnoides // Proc. Natl. Acad. Sci., India, Sect. B. Biol. Sci. 2015. DOI: 10.1007/s40011-0150646-2.

12. Truta E., Capraru G., Rosu C.M., Zamfirache M.M., Olteanu Z., Manzu C. Morphometric pattern of somatic chromosomes in three Romanian seabuckthorn genotypes // Caryologia. 2011. Vol. 64. N 2. P. 189-196.

13. Zhou X., Ma J., Wang W., Gong N., Liu J. Genome size of the diploid hybrid species Hippophae goniocarpa and its parental species, $H$. rhamnoides ssp. sinensis and $H$. neurocarpa ssp. neurocarpa (Elaeagnaceae) // Acta Biol. Cracoviensia Ser. Bot. 2010 Vol. 52. N 2. P. 12-16.

14. Doyle J.J., Doyle J.L. Isolation of plant DNA from fresh tissue // Focus. 1990. Vol. 12. N 1. P. 13-15.

15. GeneDoc: Analysis and visualization of genetic variation [Электронный ресурc]. 1997. URL: http://www.nrbsc. org/gfx/genedoc/ebinet.htm (дата обращения: 10.08.2016).

16. Negi M.S., Rajagopal J., Chauhan N., Cronn R., Lakshmikumaran $M$. Length and sequence heterogeneity in 5S rDNA of Populus deltoides // Genome. 2002. Vol. 45. N 6. P. $1181-1188$.

17. Fernández M., Ruiz M.L., Linares C., Fominaya A., Pérez de la Vega M. 5S rDNA genome regions of Lens species // Genome. 2005. Vol. 48. N 5. P. 937-942.

18. Cruz V.P., Oliveira C., Foresti F. An intriguing model for $5 \mathrm{~S}$ rDNA sequences dispersion in the genome of fresh- water stingray Potamotrygon motoro (Chondrichthyes: Potamotrygonidae) // Mol. Biol. 2015. Vol. 49. N 3. P. 466-469.

19. Campo D., Machado-Schiaffino G., Horreo J.L., Garcia-Vazquez E. Molecular organization and evolution of 5S rDNA in the genus Merluccius and their phylogenetic implications // J. Mol. Evol. 2009. Vol. 68. N 3. P. 208-216.

20. Deiana A.M., Cau A., Salvadori S., Coluccia E., Cannas R., Milia A. Tagliavini J. Major and 5S ribosomal sequences of the largemouth bass Micropterus salmoides (Perciformes, Centrarchidae) are localized in GC-rich regions of the genome // Chromosome Res. 2000. Vol. 8. N 3. P. 213-218.

21. Moran P., Garcia-Vazquez E. Identification of highly prized commercial fish using a PCR-based methodology // Biochem. Mol. Biol. Educ. 2006. Vol. 34. N 2. P. 121-124.

22. Ota K., Tateno Y., Gojobori T. Highly differentiated andconserved sex chromosome in fish species (Aulopus japonicus: Teleostei, Aulopidae) // Gene. 2003. Vol. 317. N 1-2. P. 187-193.

23. Gornung E., De Innocentilis S., Annesi F., Sola L. Zebrafish 5S rRNA genes map to the long arms of chromosome 3 // Chromosome Res. 2000.Vol. 8. N 4. P. 362.

24. Gaskin J.F., Hufbauer R.A., Bogdanowicz S.M. Microsatellite markers for Russian olive (Elaeagnus angustifolia; Elaeagnaceae) // Appl. Plant Sci. 2013. Vol. 1. N 9. P. 1300013.

25. Zhang Q. Zhu X.T. Microsatellite DNA loci from the drought desert plant Calligonum mongolicum Turcz. (Polygonaceae) // Con. Gen. 2009. Vol. 10. N 6. P. 1891-1893.

Поступила в редакцию 11.08.2016 Принята в печать 09.09.2016

\title{
MOLECULAR BIOLOGY
}

\section{MOLECULAR GENETIC FEATURES OF 5S rDNA NON-TRANSCRIBED SPACER IN HIPPOPHAE RHAMNOIDES L.}

\author{
O.S. Alexandrov*, A.V. Evtukhov, I.I. Kiselev, G.I. Karlov \\ Centre for Molecular Biotechnology, Russian State Agrarian University - Moscow Timiryazev \\ Agricultural Academy; Timiryazevskaya ul. 49, Moscow, 127550, Russia \\ *e-mail: olegsandrov@gmail.com
}

Amplification of sea buckthorn Hippophae rhamnoides L. 5S rDNA non-transcribed spacer with coding border anneal primers showed existence of single fragment. The fragment was cloned and sequenced. It was shown that length of the Hippophae rhamnoides L. 5S rDNA nontranscribed spacer is $807 \mathrm{bp}$. Analysis of the sequence allowed to detect a high homology with early described microsatellite locuses of Hippophae rhamnoides L., russian olive Elaeagnus angustifolia L. and Calligonum mongolicum Turcz., that include a (GA) ${ }_{9}$ motif. These results may be useful to study a ribosomal RNA gene organization.

Keywords: $5 S$ rDNA, non-transcribed spacer, microsatellite locus, Hippophae rhamnoides L., Elaeagnus angustifolia L., Calligonum mongolicum Turcz.

\section{Сведения об авторах}

Александров Олег Сергеевич - канд. биол. наук, ст. науч. сотр. Центра молекулярной биотехнологии ФГБОУ ВО РГАУ - МСХА имени К.А. Тимирязева. Тел.: 8-499-977-72-01; e-mail: olegsandrov@gmail.com

Евтухов Алексей Владимирович - лаборант-исследователь Центра молекулярной биотехнологии ФГБОУ ВО РГАУ - МСХА имени К.А. Тимирязева. Тел.: 8-499-977-72-01; e-mail: a_evtukhov@mail.ru

Киселёв Илья Игоревич - аспирант Центра молекулярной биотехнологии ФГБОУ ВО РГАУ - МСХА имени К.А. Тимирязева. Тел.: 8-499-977-72-01; e-mail: der dietrich@mail.ru

Карлов Геннадий Ильич - докт. наук, руководитель Центра молекулярной биотехнологии ФГБОУ ВО РГАУ - МСХА имени К.А. Тимирязева. Тел.: 8-499-977-72-01; e-mail: karlovg@gmail.ru 